\title{
In Silico Search of Energy Metabolism Inhibitors for Alternative Leishmaniasis Treatments
}

\author{
Lourival A. Silva, ${ }^{1,2}$ Marina C. Vinaud, ${ }^{2,3}$ Ana Maria Castro, ${ }^{1,3}$ \\ Pedro Vítor L. Cravo, ${ }^{2,3}$ and José Clecildo B. Bezerra ${ }^{2,3}$ \\ ${ }^{1}$ Federal Institute of Education, Science and Technology of Goiânia, 76300000 Ceres, GO, Brazil \\ ${ }^{2}$ Goiás Network of Research in Biotechnology and Metabolomics of the Host-Parasite Relationship, \\ Goiás Research Support Foundation (FAPEG), 74605050 Goiânia, GO, Brazil \\ ${ }^{3}$ Institute of Tropical Pathology and Public Health, Federal University of Goiás, 74605050 Goiânia, GO, Brazil \\ Correspondence should be addressed to Pedro Vítor L. Cravo; pedrovcravo@gmail.com
}

Received 5 July 2014; Revised 8 August 2014; Accepted 14 September 2014

Academic Editor: Suresh Sundaram

Copyright (C) 2015 Lourival A. Silva et al. This is an open access article distributed under the Creative Commons Attribution License, which permits unrestricted use, distribution, and reproduction in any medium, provided the original work is properly cited.

Leishmaniasis is a complex disease that affects mammals and is caused by approximately 20 distinct protozoa from the genus Leishmania. Leishmaniasis is an endemic disease that exerts a large socioeconomic impact on poor and developing countries. The current treatment for leishmaniasis is complex, expensive, and poorly efficacious. Thus, there is an urgent need to develop more selective, less expensive new drugs. The energy metabolism pathways of Leishmania include several interesting targets for specific inhibitors. In the present study, we sought to establish which energy metabolism enzymes in Leishmania could be targets for inhibitors that have already been approved for the treatment of other diseases. We were able to identify 94 genes and 93 Leishmania energy metabolism targets. Using each gene's designation as a search criterion in the TriTrypDB database, we located the predicted peptide sequences, which in turn were used to interrogate the DrugBank, Therapeutic Target Database (TTD), and PubChem databases. We identified 44 putative targets of which 11 are predicted to be amenable to inhibition by drugs which have already been approved for use in humans for 11 of these targets. We propose that these drugs should be experimentally tested and potentially used in the treatment of leishmaniasis.

\section{Introduction}

Leishmaniasis affects 12 million people worldwide, and approximately 350 million people from 98 countries are at risk of contracting the disease [1]. Leishmaniasis is caused by approximately 20 distinct species of Leishmania and is transmitted by two genera of phlebotomine sandflies: Phlebotomus in the Old World and Lutzomyia in the New World. From a clinical point of view, leishmaniasis is classified as cutaneous, mucocutaneous, or visceral; the latter is a severe form of the disease that becomes fatal if left untreated $[1,2]$. As effective vaccines are unfortunately not available for either animals or humans, prevention is restricted to the combat of vectors, control of reservoirs, and treatment of affected individuals $[3,4]$.
The drugs currently approved for the treatment of leishmaniasis are directed at various molecular targets. Pentavalent antimonials interfere with the synthesis of DNA, $\beta$ oxidation of fatty acids, phosphorylation of ADP, and inhibition of glycolysis. Amphotericin B exhibits a high affinity for ergosterol, which is an important component of the cell membrane in fungi and Leishmania. Miltefosine induces apoptosis as a consequence of its intracellular accumulation. Although paromomycin inhibits cytochrome C in Candida krusei, its mechanism of action in Leishmania has not yet been elucidated; it is believed that its site of action is in the mitochondria, where it possibly interferes with the synthesis of proteins by hindering the translocation and recycling of ribosomal subunits. Pentamidine appears to reduce the membrane potential and inhibits the enzyme topoisomerase 
in the mitochondria [5]. However, all of these drugs exhibit serious problems, including drug resistance (antimonials), severe side effects (amphotericin and miltefosine), and a prohibitively high cost for use in a public healthcare setting (paromomycin and miltefosine) [6-8]. For these reasons, there is an urgent need for new drugs against leishmaniasis.

Although drugs may target lipids, nucleic acids, or polysaccharides, the drugs with the greatest efficacy are directed against protein targets [9]. The energy metabolism pathways of Leishmania include several protein targets that are interesting for the development or testing of new drugs $[10,11]$. Glycosomes (similar to mammal peroxisomes) and mitochondria are the main sites of energy production in the promastigote forms of Leishmania. The glycosome is the site of glycolysis, which consists of seven reactions that break glucose down into two pyruvate molecules, while the mitochondria are the sites of the Krebs cycle and oxidative phosphorylation. In addition to glucose, amino acids are also important sources of energy. The final products of promastigote metabolism are carbon dioxide, succinate, pyruvate, Dlactate, alanine, ammonia, and urea [10]. The inhibition of one or more enzymes at each of these metabolic steps represents progress in the elimination of the parasite.

Prior to targeting a metabolic pathway, its importance for both the parasite and the host must be taken into consideration. The selectivity of inhibitors is also important, that is, how much they are able to inhibit a parasitic enzyme without causing any damage to the host [11]. Several enzymes in the Leishmania glycolytic pathway have been indicated as interesting therapeutic targets, including hexokinase, fructose-1,6-bisphosphate aldolase, triosephosphate isomerase, glyceraldehyde-3-phosphate dehydrogenase, phosphoglycerate kinase, pyruvate kinase, and glycerol3-phosphate dehydrogenase [11]. However, the following question remains unanswered: which drugs inhibit these or other enzymes involved in the energy metabolism of Leishmania?

In general, the strategy for drug development includes both de novo discovery and the improvement of inhibitors of individually validated targets. Although this strategy is efficient for the development of new drugs against leishmaniasis, it is time-consuming and expensive. One interesting alternative approach is a strategy commonly known as drug repositioning. Drug repositioning makes use of known genomic data to search for drugs already approved for clinical use in humans for other diseases and for which the drug targets are already known. This approach uses the principle of "target homology" and can be put in practice using bioinformatics drug-target repositories, such as DrugBank [12] and Therapeutic Targets Database [13]. Such chemogenomics strategies considerably increase the likelihood of success in drug discovery, cutting down the costs and time spent in the process of research and development, in comparison with "traditional" methodologies. For this reason, pharma industries are increasingly using drug repositioning in order to find alternative applications for their drugs, reducing time and costs involved in the process of developing new compounds $[14,15]$.
In the present study, we used the concept of drug repositioning to identify new drugs with potential activity against Leishmania parasites. We first used genomic data to compile a list of energy metabolism drug targets in Leishmania of possible therapeutic interest. Each of these potential targets was then used as query in databases that include information on thousands of therapeutic compounds active against specific protein targets, the metabolic pathways that are involved, and the diseases for which they have been tested or for which clinical tests are currently in progress $[12,13,16-19]$.

\section{Materials and Methods}

2.1. Compilation of a List of Potential Leishmania Energy Metabolism Targets. A list of hypothetic targets was extracted from the database TDR Targets (http://tdrtargets.org). TDR Targets is a project of the World Health Organization that prioritizes neglected tropical diseases. The database has open access and provides genomic information on specific species that allows users to identify and prioritize targets of interest $[15,20]$. We selected targets on the first page, and in the first field, we selected L. major as the pathogenic species of interest. The next field provided a filter based on the following: Name/Annotation, Features, Structures, Expression, Antigenicity, Phylogenetic distribution, Essentiality, Validation data, Druggability, Assayability, and Bibliographic references. We decided to limit the number of filters to increase the odds that the search would produce results. Despite this, some of the genes related to Leishmania energy metabolism could not be found in the TDR Targets database. For this reason, we expanded the filter Name/Annotation and chose the option "Energy metabolism" in the field KEGG high-level pathway. Next, we expanded the filter Druggability and selected a druggability evidence range (which varies from zero to one) $\geq 0.2$ in the option Druggability index. This query was automatically saved in the my history section; the results were organized into a table that could be uploaded.

\subsection{Identification of Potential Drug Targets in Available} Drug Databases: General Strategy. We ran searches of the name of each gene identified as TDR Targets in the database TriTrypDB (http://tritrypdb.org/tritrypdb/), which contains genomic information on pathogens of the family Trypanosomatidae, to which the genera Leishmania and Trypanosoma belong [21]. In the TriTrypDB homepage, we wrote the names of the genes in the field Gene ID and selected the search option. We checked each gene's name and product and extracted their predicted peptide sequences. In the cases of known enzymes whose encoding genes could not be identified among the TDR Targets, we wrote the enzyme name in the field Gene Text Search to run the search. Every Leishmania predicted peptide was considered as a potential target, and the sequences were used to run searches in the online databases DrugBank (http://www.drugbank.ca/) and Therapeutic Target Database (TTD) (http://bidd.nus.edu.sg/group/TTD/ttd.asp), which 
provide basic information on drugs and their primary or hypothetical targets.

DrugBank is an open-access database that provides users with information on drugs (chemical, pharmaceutical, and pharmacological data) and their targets (sequence, structure, and metabolic pathway). The database currently contains data on approximately 8,000 agents, including 1,700 drugs already approved by the FDA (Food and Drug Administration) and 6,000 experimental drugs [12, 17, 22]. The TTD stores information on 2,400 targets and approximately 21,000 drugs, of which 2,000 are already approved and 460 are currently undergoing clinical testing. In addition, it provides information on targets, such as sequence, function, metabolic pathway, and three-dimensional structure, through links to other relevant databases $[13,18,19]$.

In both databases, our search strategy was based on the target-similarity principle, whereby each command (energy metabolism enzymes in Leishmania) was compared by similarity to all known drug targets included in all of the abovementioned databases. Whenever homologous drug targets were identified, all of the proteins with an output expectation value ( $E$-value) less than $1 E-5$ relative to all three databases were included in the list of potential targets [14]. From this list, we selected the targets that interact with compounds that are already approved for clinical use in humans. Additional information on each drug was obtained from the PubChem database (https://pubchem.ncbi.nlm.nih.gov/).

2.3. Compilation of a List of Predicted Targets. Following the search of all of the enzymes involved in Leishmania energy metabolism in the two databases, all of the proteins for which the search results were negative were discarded. The remaining predicted targets from each database were compiled for the target spreadsheet provided by the TDR Targets. The following parameters associated with each positive hit were introduced in the spreadsheet: "Homologous target(s) name(s) and target ID(s)" (DrugBank and TTD), "Evalue(s)" (DrugBank and TTD), "Drug type(s)" (DrugBank and TTD), "Drug name(s)" (DrugBank and TTD), "Drug ID(s)" (DrugBank), "Toxicity" (DrugBank), and Drug ID(s) and CID (PubChem).

2.4. List of Drugs for In Vitro Tests against Leishmania spp. In addition to the information gathered from the PubChem database, we performed a literature search of the PubMed database of approved drugs that have not yet been tested against Leishmania. We searched for all of the drugs associated with each positive hit on our list. Our definition of "test" included in vivo and/or in vitro tests and any species of Leishmania. Drugs were classified as "untested" when no related publication could be found. In these cases, one of the following search terms was introduced in PubMed: (1) ("drug name"[MeSH Terms] OR "drug name"[All Fields]) AND ("Leishmania"[-MeSH Terms] OR "Leishmania"[All Fields]) and (2) ("drug name"[MeSH Terms] OR "drug name"[All Fields]) AND ("Leishmaniasis" [MeSH Terms] OR "Leishmaniasis"[All Fields]). Drugs were also classified as "untested" when the information provided by the located

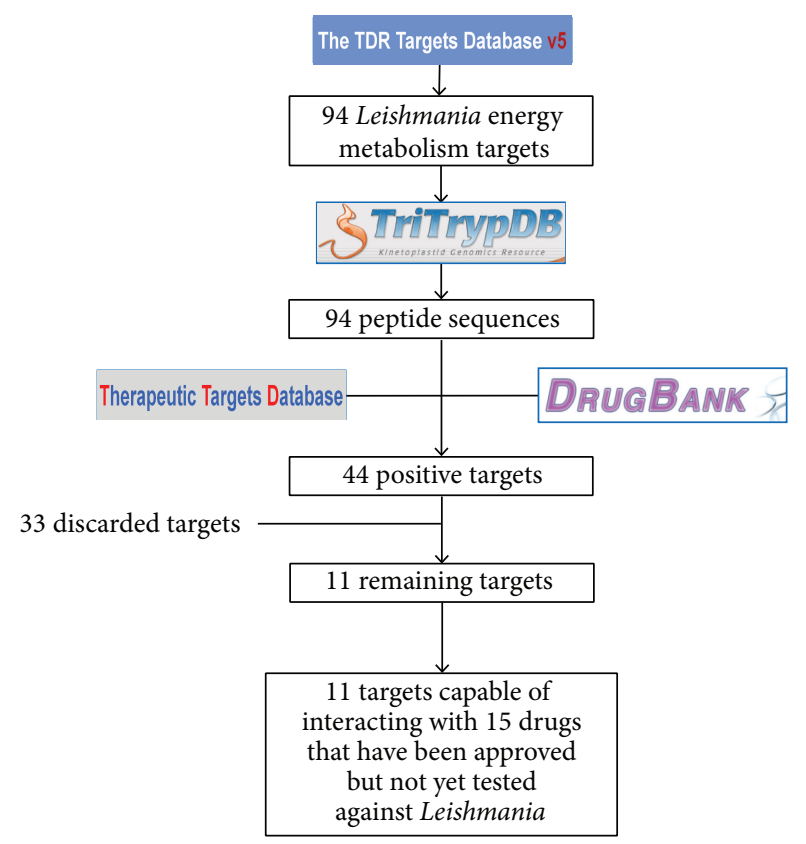

FIGURE 1: Flowchart depicting the overall strategy and results of this work.

study(ies) was insufficient to infer the potential usefulness of the drug as a leishmanicidal agent.

\section{Results}

3.1. Compilation of a List of Predicted Targets. To clarify the procedure we used for the identification and selection of the energy metabolism targets, all of the steps are depicted in Figure 1. We identified 94 genes associated with the energy of Leishmania. All of the products of these genes were considered as potential therapeutic targets. The predicted amino acid sequence of all these peptides was searched based on target similarity in the databases TTD and DrugBank.

A list of 44 positive hits (approximately $47 \%$ of the predicted peptides corresponding to Leishmania energy metabolism) was generated. Two databases were used to avoid missing important targets because the information they contained on drug targets was not the same (Figure 1). We identified 26 predicted targets in TTD, four of which appeared only in this database, and 40 predicted targets in the DrugBank database, 14 of which were exclusive to it. Twelve of the targets are enzymes that participate in glycolysis and/or the Krebs cycle, 13 participate in oxidative phosphorylation, and 11 participate in amino acid metabolism.

From the list of positive hits, we selected targets that had been previously tested in any organism and that had a corresponding commercially available drug. Detailed information on these targets and the corresponding compounds is provided in Table 1 .

3.2. Untested Drugs. To establish which target-related drugs had been previously tested against leishmaniasis, we performed a literature search in the PubMed database, as 
TABLE 1: New drug-target associations disclosed in the present study.

\begin{tabular}{|c|c|c|c|c|c|}
\hline Drug (brand names) & Drug category(ies) & Toxicity & Leishmania target(s) ID & Identity to ( $E$-value) & $\begin{array}{c}\text { TDRT } \\
\text { druggability }\end{array}$ \\
\hline $\begin{array}{l}\text { Lonidamine } \\
\text { (Doridamina) }\end{array}$ & $\begin{array}{c}\text { Anticancer, } \\
\text { antitrypanosomal }\end{array}$ & NA & $\begin{array}{l}\text { Hexokinase, putative } \\
\text { LbrM.21.0310 }\end{array}$ & $\begin{array}{c}\text { Hexokinase D } \\
(3 E-54) \\
\end{array}$ & NA \\
\hline POLYSIN & Antiprotozoal & NA & $\begin{array}{l}\text { ATP-dependent } \\
\text { phosphofructokinase } \\
\text { LbrM.29.2480 }\end{array}$ & $\begin{array}{c}\text { Pyrophosphate- } \\
\text { dependent } \\
\text { phosphofructokinase } \\
(2.00 E-06)\end{array}$ & NA \\
\hline Saframycin A & Anticancer & NA & $\begin{array}{l}\text { Glyceraldehyde } \\
\text { 3-phosphate } \\
\text { dehydrogenase } \\
\text { LbrM.30.2950 }\end{array}$ & $\begin{array}{c}\text { Glyceraldehyde } \\
\text { 3-phosphate } \\
\text { dehydrogenase, muscle } \\
2 E-91\end{array}$ & NA \\
\hline Nadide & $\begin{array}{l}\text { Chagas disease, } \\
\text { parasitic diseases, and } \\
\text { sleeping sickness }\end{array}$ & $\begin{array}{l}\text { No reports of overdose; } \\
\text { however, high doses of } \\
\text { NADH (10 mg a day or } \\
\text { more) may cause } \\
\text { jitteriness, anxiety, and } \\
\text { insomnia }\end{array}$ & $\begin{array}{l}\text { Glycerol-3-phosphate } \\
\text { dehydrogenase } \\
\text { LbrM.10.0640 }\end{array}$ & $\begin{array}{l}\text { Glycerol-3-phosphate } \\
\text { dehydrogenase }[\mathrm{NAD}+] \\
\text { cytoplasmic } \\
2 E-31\end{array}$ & 0.2 \\
\hline $\begin{array}{l}\text { Sulfacetamide; } \\
\text { sulfanilamide; } \\
\text { sulfoxone }\end{array}$ & Bacterial infections & $\begin{array}{l}\text { Oral LD50 mouse: } \\
16500 \mathrm{mg} / \mathrm{kg} \text {. Side effects } \\
\text { include moderate to } \\
\text { severe erythema } \\
\text { (redness) and moderate } \\
\text { edema (raised skin), } \\
\text { nausea, vomiting, } \\
\text { headache, dizziness, and } \\
\text { tiredness. Higher } \\
\text { exposure causes } \\
\text { unconsciousness } \\
\end{array}$ & $\begin{array}{l}\text { Phosphomannose } \\
\text { isomerase (PMI) } \\
\text { LbrM.32.1750 }\end{array}$ & $\begin{array}{c}\text { Mannose-6-phosphate } \\
\text { isomerase } \\
3 E-59\end{array}$ & 0.6 \\
\hline $\begin{array}{l}\text { Morantel tartrate, } \\
\text { oxantel pamoate, and } \\
\text { thiabendazole }\end{array}$ & $\begin{array}{c}\text { Helicobacter pylori } \\
\text { infection, Mature } \\
\text { gastrointestinal } \\
\text { nematode infections, } \\
\text { Trichuris trichiura } \\
\text { infection }\end{array}$ & $\begin{array}{l}\text { Overdosage may be } \\
\text { associated with transient } \\
\text { disturbances of vision } \\
\text { and psychic alterations }\end{array}$ & $\begin{array}{l}\text { NADH-dependent } \\
\text { fumarate reductase } \\
\text { LbrM.34.0820 }\end{array}$ & $\begin{array}{l}\text { Fumarate reductase } \\
\text { flavoprotein subunit } \\
2.00 E-13\end{array}$ & 0.5 \\
\hline $\begin{array}{l}\text { CEPHARANTHINE; } \\
\text { CONESSINE }\end{array}$ & $\begin{array}{c}\text { African } \\
\text { trypanosomiasis; } \\
\text { Chagas disease; } \\
\text { Leishmania infections; } \\
\text { parasitic diseases; }\end{array}$ & NA & $\begin{array}{l}\text { Trypanothione } \\
\text { reductase } \\
\text { LmjF05.0350 }\end{array}$ & $\begin{array}{l}\text { Glutathione reductase, } \\
\text { mitochondrial } \\
6 E-65\end{array}$ & NA \\
\hline $\begin{array}{l}\text { Aciglut, Glusate, } \\
\text { Glutacid, Glutamicol, } \\
\text { Glutamidex, } \\
\text { Glutaminol, and } \\
\text { Glutaton }\end{array}$ & $\begin{array}{c}\text { Antibacterial; } \\
\text { antitrypanosomal }\end{array}$ & $\begin{array}{l}\text { Glutamate causes } \\
\text { neuronal damage and } \\
\text { eventual cell death, } \\
\text { particularly when the } \\
\text { NMDA receptors are } \\
\text { activated. High dosages } \\
\text { of glutamic acid may } \\
\text { include symptoms such } \\
\text { as headaches and } \\
\text { neurological problems }\end{array}$ & $\begin{array}{l}\text { Aspartate } \\
\text { aminotransferase, } \\
\text { putative LbrM.24.0370 }\end{array}$ & $\begin{array}{c}\text { Aspartate } \\
\text { aminotransferase, } \\
\text { mitochondrial } \\
8 E-89\end{array}$ & 0.3 \\
\hline $\begin{array}{l}\text { 2-Oxopropanoic acid, } \\
\text { pyroracemic acid, and } \\
\text { acetylformic acid }\end{array}$ & Bacterial infections & & $\begin{array}{l}\text { Pyruvate kinase } \\
\text { LbrM.34.0010 }\end{array}$ & $\begin{array}{c}\text { Pyruvate kinase } \\
1.00 E-117\end{array}$ & NA \\
\hline $\begin{array}{l}\text { Succinic acid } \\
\text { (Katasuccin, Kyselina } \\
\text { jantarova) }\end{array}$ & NA & $\begin{array}{l}\text { Oral rat LD50: } \\
2260 \mathrm{mg} / \mathrm{kg}\end{array}$ & $\begin{array}{l}\text { Succinate } \\
\text { dehydrogenase } \\
\text { LmjF15.0990 }\end{array}$ & $\begin{array}{l}\text { Succinate dehydrogenase } \\
\text { [ubiquinone] iron-sulfur } \\
\text { subunit, mitochondrial } \\
\qquad 2 E-28\end{array}$ & NA \\
\hline
\end{tabular}


TABle 1: Continued.

\begin{tabular}{|c|c|c|c|c|c|}
\hline Drug (brand names) & Drug category(ies) & Toxicity & Leishmania target(s) ID & Identity to ( $E$-value) & $\begin{array}{c}\text { TDRT } \\
\text { druggability }\end{array}$ \\
\hline $\begin{array}{l}\text { Adenovite, } \\
\text { Cardiomone, } \\
\text { Lycedan, My-B-Den, } \\
\text { Phosaden, and } \\
\text { Phosphaden }\end{array}$ & NA & NA & $\begin{array}{l}\text { Acetyl-coenzyme A } \\
\text { synthetase, putative } \\
\text { LbrM.23.0580 }\end{array}$ & $\begin{array}{c}\text { Acetyl-coenzyme A } \\
\text { synthetase, cytoplasmic } \\
3 E-159\end{array}$ & 0.2 \\
\hline
\end{tabular}

described above. We found that only one of the target-related compounds had been previously tested against leishmaniasis.

\section{Discussion}

The aim of the present study was to identify drugs that are specifically active against Leishmania energy metabolism enzymes and have been previously tested against nonparasitic diseases or other human parasitic diseases. Below, we discuss the identified drugs and their effects on Leishmania energy metabolism.

Lonidamine (Doridamina) (LND, (1-[(2,4-dichlorophenyl)methyl]-1H-indazole-3-carboxylic acid) was developed as an antispermatogenic agent that proved to be effective against cells with high metabolic activity, such as cancer and protozoan cells $[23,24]$. In tumor cells, LND impairs glycolysis and lactate production by inhibiting mitochondrial hexokinase [23]. This inhibition was achieved with a lethal dose (LD50) of $\sim 260 \mu \mathrm{M}$ and $\sim 80 \mu \mathrm{M}$ in L. mexicana promastigote forms and Trypanosoma cruzi epimastigote forms, respectively. The mechanism of action of LND was attributed to inhibition of the energy metabolism [23]. In Trypanosoma brucei, which causes African trypanosomiasis, LND inhibits the enzyme hexokinase in the procyclic forms of the parasite, indicating that hexokinase is a relevant therapeutic target for LND [25].

Nadide has been approved for the treatment of Parkinson's disease, Alzheimer's disease, and cardiovascular diseases (DrugBank data). Recent studies on breast cancer and longevity have revealed the importance of this small molecule. Nadide is the commercial form of the NADH molecule that living organisms produce through the reduction of nicotinamide adenine dinucleotide (NAD).

Appreciation of the importance of this small molecule has greatly increased since it was discovered at the beginning of the 20th century. The best-known role of NAD is as an electron carrier in oxidation-reduction reactions. However, several other functions have been attributed to it, including signal transduction and protein and DNA modification [26]. Recently, [27] reported that NAD+ homeostasis is crucial for Leishmania biology and virulence. The authors showed that nicotinamidase, which catalyzes the conversion of nicotinamide into nicotinic acid, is the key enzyme for the production of $\mathrm{NAD}+$ from its precursors.Interestingly, the involved precursors (nicotinamide, nicotinic acid, and nicotinamide riboside) are derived from the host, and nicotinamidase cannot be found in mammals [27].

Sodium sulfacetamide or sulfacetamide is a bacteriostatic agent that is active against sulfonamide-sensitive Gramnegative and Gram-positive bacteria, including Streptococci, Staphylococci, E. coli, Klebsiella pneumoniae, Pseudomonas pyocyanea, Salmonella spp., Proteus vulgaris, and Nocardia, which are usually isolated in secondary infections of the skin.

The LD50 of sulfacetamide for mice is $16,500 \mathrm{mg} / \mathrm{kg}$ by the oral route. In humans, the side effects include erythema, moderate swelling, nausea, vomiting, and headache. In addition to these side effects, the occurrence of StevensJohnson syndrome was reported in HIV-positive patients who received sulfacetamide drops for eye infections. All of these side effects, however, are associated with oral administration or high drug absorption through the skin, mucous membranes, and the conjunctiva, whereas topical use is not associated with strong side effects, except in the case of individuals with a hypersensitivity to sulfonamide.

Sulfacetamide inhibits mannose-6-phosphate isomerase (also known as phosphomannose isomerase (PMI)), which is considered the key enzyme in kinetoplastid energy metabolism. PMI catalyzes the isomerization of fructose-6phosphate into mannose-6-phosphate. As the identity of the kinetoplastid PMI with human PMI is low $(E$-value $=3 E-$ $59)$, it represents an interesting target on which to test new drugs.

\section{Conclusions}

We identified potential inhibitors of Leishmania energy metabolism by searching the information available in databases based on the target-similarity principle. Although approved for use in humans, none of the drugs identified have yet been tested against the parasite Leishmania. In vitro and in vivo tests may confirm the efficacy of these drugs, potentially leading to their use in the treatment of leishmaniasis.

\section{Appendix}

\section{Database Details and Commands}

DrugBank Database Commands. In this database, the search was initiated by selecting the options "search" and then "Sequence Search" from the toolbar menu. The sequence of 
each protein investigated was entered in FASTA format in the appropriate field, and the search parameters were selected automatically.

TTD Commands. On the homepage of this database, we selected the option "target similarity search." The sequence of the protein being investigated was entered in FASTA format in the appropriate field, and the option "search" was selected. In the cases with positive search results, only the targets with an $E$-value less than $1 E-5$ were considered for further analysis.

PubChem Database Commands. In this database, the tab "compound" was selected, and every drug identified in DrugBank and TTD was entered in the appropriate field. The PubChem database was searched to gather detailed information on each compound, including the pharmacology, patents, physical and chemical properties, results of biological tests, biological interactions, and metabolic pathways.

\section{Conflict of Interests}

The authors declare that there is no conflict of interests regarding the publication of this paper.

\section{References}

[1] J. Alvar, I. D. Vélez, C. Bern et al., "Leishmaniasis worldwide and global estimates of its incidence," PLoS ONE, vol. 7, no. 5, Article ID e35671, 2012.

[2] D. O. Santos, C. E. R. Coutinho, M. F. Madeira et al., "Leishmaniasis treatment-a challenge that remains: a review," Parasitology Research, vol. 103, no. 1, pp. 1-10, 2008.

[3] B. Chawla and R. Madhubala, "Drug targets in Leishmania," Journal of Parasitic Diseases, vol. 34, no. 1, pp. 1-13, 2010.

[4] L. M. Fidalgo and L. Gille, "Mitochondria and trypanosomatids: targets and drugs," Pharmaceutical Research, vol. 28, no. 11, pp. 2758-2770, 2011.

[5] N. Singh, M. Kumar, and R. K. Singh, "Leishmaniasis: current status of available drugs and new potential drug targets," Asian Pacific Journal of Tropical Medicine, vol. 5, no. 6, pp. 485-497, 2012.

[6] J. Kaur, R. Tiwari, A. Kumar, and N. Singh, "Bioinformatic analysis of Leishmania donovani long-chain fatty acid-CoA ligase as a novel drug target," Molecular Biology International, vol. 2011, Article ID 278051, 14 pages, 2011.

[7] M. K. Mittal, S. Rai, A. Ravinder, S. Gupta, S. Sundar, and N. Goyal, "Characterization of natural antimony resistance in Leishmania donovani isolates," The American Journal of Tropical Medicine and Hygiene, vol. 76, no. 4, pp. 681-688, 2007.

[8] S. L. Croft, S. Sundar, and A. H. Fairlamb, "Drug resistance in leishmaniasis," Clinical Microbiology Reviews, vol. 19, no. 1, pp. 111-126, 2006.

[9] A. L. Hopkins and C. R. Groom, "The druggable genome," Nature Reviews Drug Discovery, vol. 1, no. 9, pp. 727-730, 2002.

[10] F. R. Opperdoes and P. A. M. Michels, "The metabolic repertoire of Leishmania and implications for drug discovery," in Leishmania, after the Genome, pp. 123-158, Caister Academic Press, Wymondham, UK, 1st edition, 2008.
[11] C. L. Verlinde, V. Hannaert, C. Blonski et al., "Glycolysis as a target for the design of new anti-trypanosome drugs," Drug Resistance Updates, vol. 4, no. 1, pp. 50-65, 2001.

[12] D. S. Wishart, C. Knox, A. C. Guo et al., "DrugBank: a knowledgebase for drugs, drug actions and drug targets," Nucleic Acids Research, vol. 36, no. 1, pp. D901-D906, 2008.

[13] F. Zhu, B. Han, P. Kumar et al., "Update of TTD: therapeutic target database," Nucleic Acids Research, vol. 38, no. 1, pp. D787D791, 2009.

[14] N. A. Bispo, R. Culleton, L. A. Silva, and P. Cravo, "A systematic in silico search for target similarity identifies several approved drugs with potential activity against the Plasmodium falciparum apicoplast," PLoS ONE, vol. 8, no. 3, Article ID e59288, 2013.

[15] M. P. Magariños, S. J. Carmona, G. J. Crowther et al., "TDR targets: a chemogenomics resource for neglected diseases," Nucleic Acids Research, vol. 40, no. 1, pp. D1118-D1127, 2012.

[16] C. Knox, V. Law, T. Jewison et al., "DrugBank 3.0: a comprehensive resource for "Omics" research on drugs," Nucleic Acids Research, vol. 39, no. 1, pp. D1035-D1041, 2011.

[17] V. Law, C. Knox, Y. Djoumbou et al., "DrugBank 4.0: shedding new light on drug metabolism," Nucleic Acids Research, vol. 42, no. 1, pp. D1091-D1097, 2014.

[18] X. Chen, Z. L. Ji, and Y. Z. Chen, “TTD: therapeutic target database," Nucleic Acids Research, vol. 30, no. 1, pp. 412-415, 2002.

[19] F. Zhu, Z. Shi, C. Qin et al., "Therapeutic target database update 2012: a resource for facilitating target-oriented drug discovery," Nucleic Acids Research, vol. 40, no. 1, pp. D1128-D1136, 2012.

[20] G. J. Crowther, D. Shanmugam, S. J. Carmona et al., "Identification of attractive drug targets in neglected- disease pathogens using an in Silico approach," PLoS Neglected Tropical Diseases, vol. 4, no. 8, article e804, 2010.

[21] M. Aslett, C. Aurrecoechea, M. Berriman et al., "TriTrypDB: a functional genomic resource for the Trypanosomatidae," Nucleic Acids Research, vol. 38, no. 1, Article ID gkp851, pp. D457-D462, 2010.

[22] D. S. Wishart, C. Knox, A. C. Guo et al., "DrugBank: a comprehensive resource for in silico drug discovery and exploration," Nucleic Acids Research, vol. 34, pp. D668-D672, 2006.

[23] A. Floridi, M. G. Paggi, S. D’Atri et al., "Effect of lonidamine on the energy metabolism of Ehrlich ascites tumor cells," Cancer Research, vol. 41, pp. 4661-4666, 1981.

[24] E. R. Sharlow, T. A. Lyda, H. C. Dodson et al., "A target-based high throughput screen yields Trypanosoma brucei hexokinase small molecule inhibitors with antiparasitic activity," PLoS Neglected Tropical Diseases, vol. 4, no. 4, 2010.

[25] J. W. Chambers, M. L. Fowler, M. T. Morris, and J. C. Morris, "The anti-trypanosomal agent lonidamine inhibits Trypanosoma brucei hexokinase 1," Molecular and Biochemical Parasitology, vol. 158, no. 2, pp. 202-207, 2008.

[26] L. Chen, R. Petrelli, K. Felczak et al., "Nicotinamide adenine dinucleotide based therapeutics," Current Medicinal Chemistry, vol. 15, no. 7, pp. 650-670, 2008.

[27] E. Gazanion, D. Garcia, R. Silvestre et al., “The Leishmania nicotinamidase is essential for NAD+ production and parasite proliferation," Molecular Microbiology, vol. 82, no. 1, pp. 21-38, 2011. 

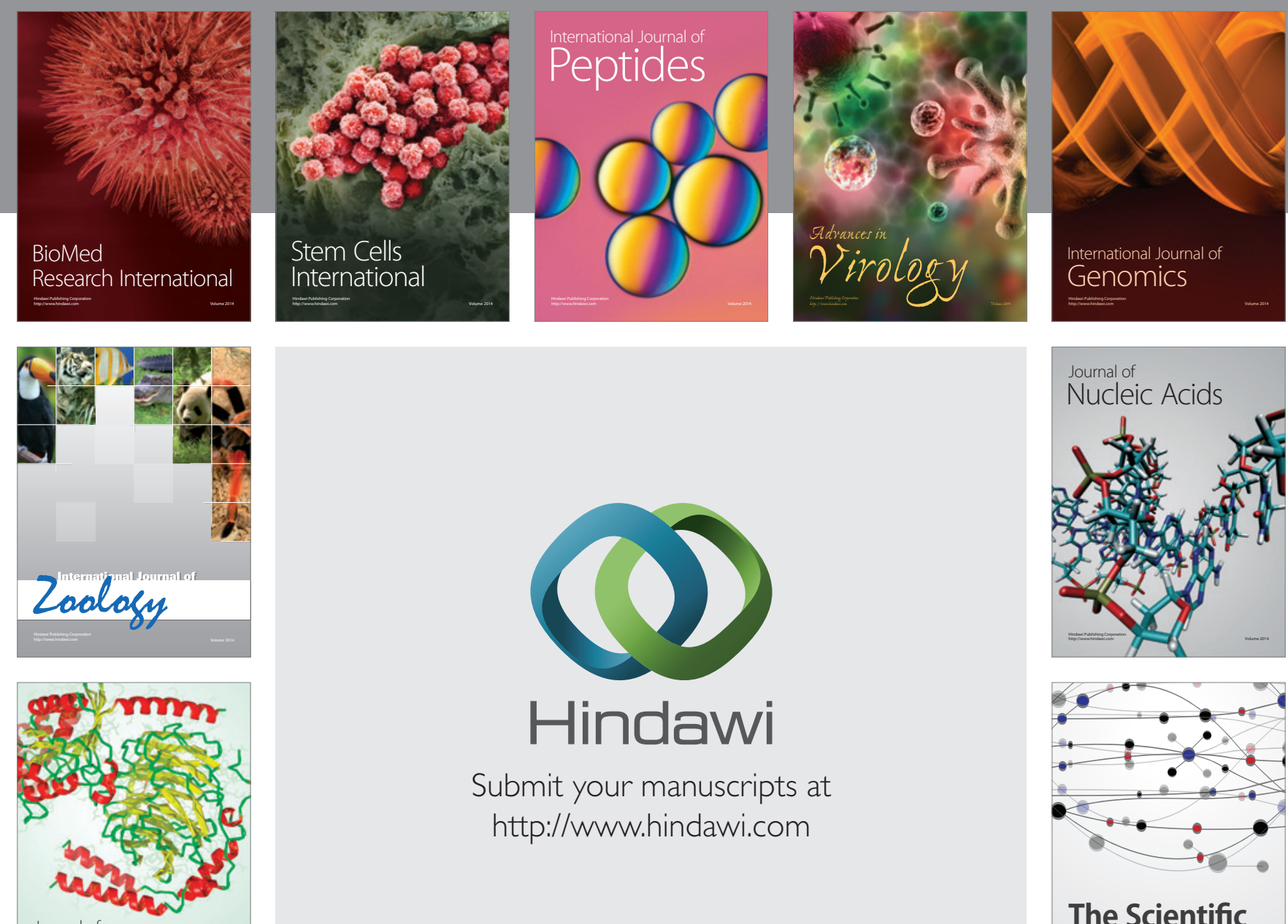

Submit your manuscripts at

http://www.hindawi.com

Journal of
Signal Transduction
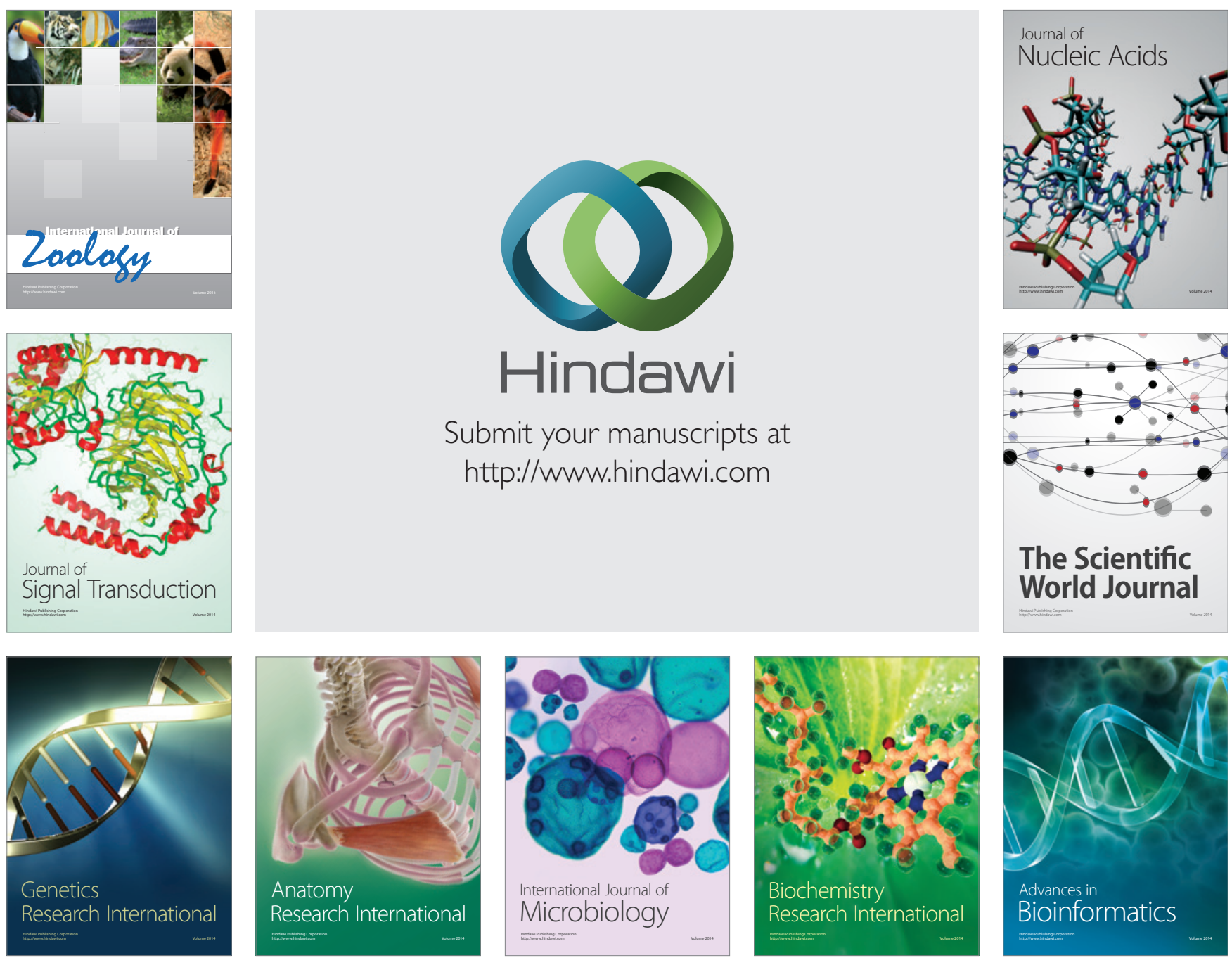

The Scientific World Journal
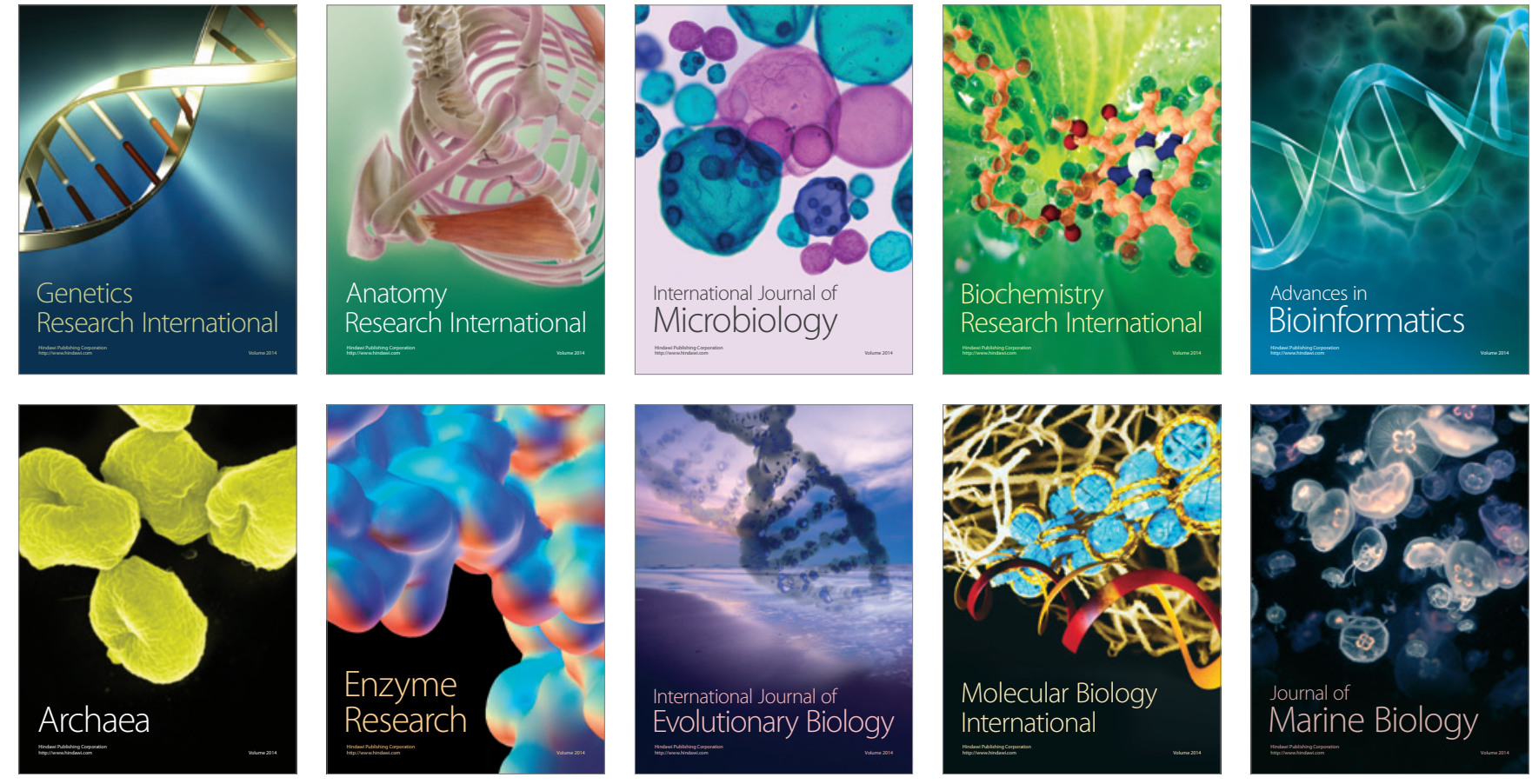